\title{
Feeding ecology of long-finned pilot whales Globicephala melas in the western North Atlantic
}

\author{
Damon P. Gannon ${ }^{1, *}$, Andrew J. Read ${ }^{1, * *}$, James E. Craddock ${ }^{1}$, Kurt M. Fristrup ${ }^{1, * * *}$, \\ John R. Nicolas ${ }^{2}$ \\ 'Woods Hole Oceanographic Institution, Woods Hole, Massachusetts 02543, USA \\ ${ }^{2}$ National Marine Fisheries Service, Woods Hole, Massachusetts 02543, USA
}

\begin{abstract}
Stomach contents from 30 long-finned pilot whales Globicephala melas captured incidentally in the Distant Water Fleet (DWF) mackerel fishery off the northeastern United States were examined. Several methods of assessing prey importance were used in order to construct a true representation of the pilot whale diet. Separate analyses of trace (free, durable body parts from well-digested prey) and non-trace (relatively intact prey) food matenals were conducted to address biases caused by differential rates of digestion and passage. Squids dominated the diet and long-finned squid Loligo pealei was the most important prey, but we noted large yearly fluctuations in prey importance. Metric multidimensional scaling analyses of trace and non-trace stomach contents of individual whales suggest that many animals were caught while teeding opportunistically near fishing operations, resulting in a bias of non-trace (intact) stomach contents. The diversity of prey in this study was greater than previous reports of the food habits of western North Atlantic long-finned pilot whales.
\end{abstract}

KEY WORDS: Food habits Bycatch Globicephala melas Loligo pealei

\section{INTRODUCTION}

Long-finned pilot whales Globicephala melas are believed to be important predators on the outer continental shelf of the northeastern United States (Kenney et al. 1985, Payne \& Heinemann 1993), but little is known about their feeding behavior. As with other pelagic cetaceans, direct observations of foraging are difficult. Previous reports of the food habits of longfinned pilot whales have yielded 3 dietary patterns: (1) diverse diet ( $\geq 10$ prey species) dominated by squids (Gales \& Pemberton 1992, Desportes \& Mouritsen 1993, Gannon et al. 1997); (2) restricted diet ( $\leq 3$ species) dominated by squids (Sergeant 1962, Martin et al.

•E-mail: dgannon@whoi.edu

Present addresses:

- Nicholas School of the Environment, Duke University Marine Lab, Beaufort, North Carolina 28516, USA

-.Bioacoustics Program, Laboratory of Ornithology, Cornell

University, Ithaca, New York 14850, USA
1987); and ( 3 ) restricted diet ( $\leq 3$ species) dominated by fishes (Mercer 1967, Waring et al. 1990, Overholtz \& Waring 1991). However, it is not known if these apparent dietary differences are real or merely artifacts of differences in sample sizes, sample sources, and/or analytical techniques. Several previous reports were limited by very small sample sizes (i.e. Mercer 1967 Martin et al. 1987, Waring et al. 1990, Overholtz \& Waring 1991, Gales \& Pemberton 1992, Gannon et al. 1997). Researchers have obtained pilot whale stomach contents from strandings (Martin et al. 1987, Gales \& Pemberton 1992, Gannon et al. 1997), fisheries bycatches (Waring et al. 1990, Overholtz \& Waring 1991), and whale hunts (Sergeant 1962, Mercer 1967. Desportes \& Mouritsen 1993). Investigators have used a variety of analytical techniques to quantify the diet of long-finned pilot whales, with proportion of mass and proportion of numerical abundance being the most common. The most recent studies (Gales \& Pemberton 1992, Desportes \& Mouritsen 1993, Gannon et al. 1997) quantified both intact and well-digested food remains 
to determine relative prey importance, while earlier studies relied primarily on intact food.

Stomach contents of 30 pilot whales incidentally killed in the Distant Water Fleet (DWF) fishery for Atlantic mackerel Scomber scombrus were studied. The DWF refers to foreign vessels fishing within the Exclusive Economic Zone of the United States. The DWF mackerel fishery operated along the shelf-edge off the northeastern United States during winter and spring from 1968 to 1991 (Waring et al. 1990. CUD 1995, this study). The goals in this study of long-finned pilot whales were to: (1) add to what is known about their diet; (2) make inferences about their foraging behavior; (3) investigate dietary biases associated with sample source; and (4) illustrate the wide range of results that can be obtained from different analytical techniques.

\section{METHODS}

Sample collection. Pilot whales were captured during mackerel fishing operations between February and May from 1989 to 1991. U.S. fisheries observers recorded the capture location, date, species, standard body length, and sex of each marine mammal. Capture locations are plotted in Fig. 1. Two or more whales were caught together on several occasions (see below) Capture location, length, and sex were not recorded in a few cases. Most ( $76 \%$ ) of the whales for which gen-

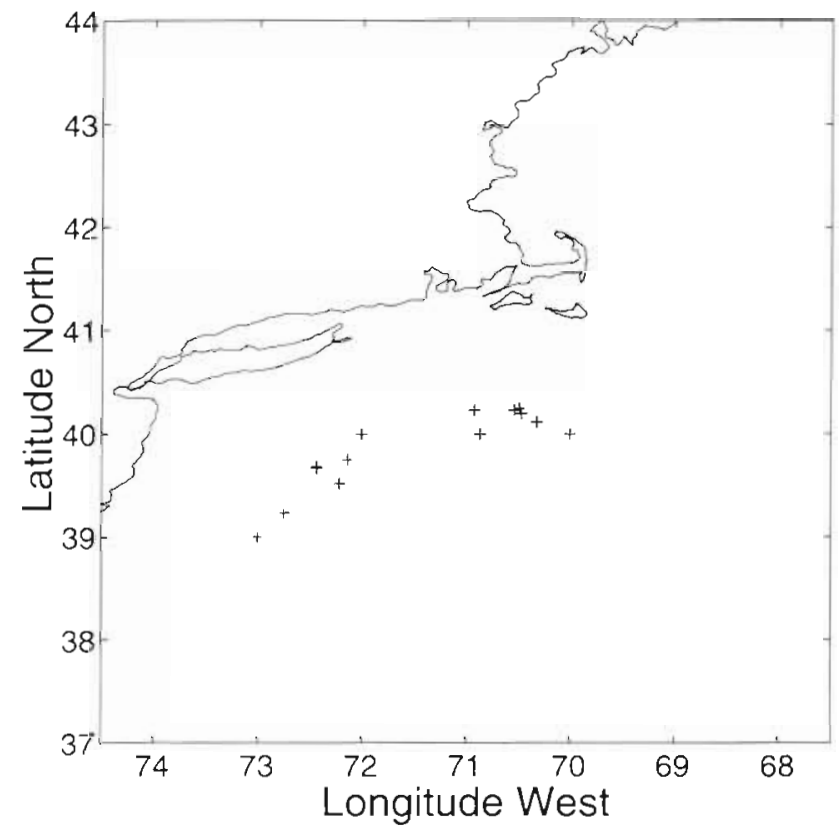

Fig. 1. Capture locations of 30 pilot whales Globicephala melas taken incidentally of the northeastern United States by the Distant Water Fleet (DWF) mackerel fishery der was known were female. Using body length as the criterion for maturity (based on morphometric data reported by Kasuya et al. 1988, Bloch et al. 1993. Desportes et al. 1993, and Martin \& Rothery 1993), the sample probably included 1 male calf, 4 juvenile females, 5 juvenile males, and 15 adult females, although it is difficult to extrapolate reproductive and maturity status from length alone. No adult males were present in the sample.

Observers extracted and froze the intact stomachs at sea. In the laboratory, food material was removed from the stomachs by hand and gentle flushing with a hose. Digesta was rinsed through a $1.0 \mathrm{~mm}$ sieve to collect hard parts.

Prey identification and prey importance. The methods used to identify prey items and assess their relative importance were identical to those of Gannon et al. (1997). Separate analyses of well-digested, or 'trace', and relatively intact, or 'non-trace', food materials were conducted. Trace prey items were those represented only by hard parts, such as otoliths, dentaries and vertebral columns for teleosts, and beaks for cephalopods. Non-trace items had soft tissue attached and permitted reasonable body length estimates to be made by direct measurement of the existing body.

Relative prey importance was assessed by 9 analytical techniques: (1) trace frequency of occurrence; (2) non-trace frequency of occurrence; (3) trace proportion of numerical abundance; (4) non-trace proportion of numerical abundance; (5) trace proportion of reconstructed mass; (6) non-trace proportion of reconstructed mass; (7) trace index of relative importance; (8) non-trace index of relative importance; and (9) modified mass. We used a wide variety of techniques to obtain a thorough understanding of the diet and to investigate the degree of variation among their results. Gannon et al. (1997) gave detailed descriptions of each method and they will be briefly reviewed here. Frequency of occurrence (FO) is the proportion of stomachs that contained a particular prey species. Proportion of numerical abundance (\%num) is the percent of prey items recovered from all stomachs represented by a particular food species. Proportion of reconstructed mass (\%mass) is the percentage of prey mass represented by each prey species. Reconstructed mass (prey mass at ingestion) was estimated by regressing on body length or on the length of hard parts (see Table 3 in Gannon et al. 1997 for a list of regression equations). When diagnostic hard parts from more than 25 trace specimens of a prey taxon were present in 1 stomach, all hard parts from that taxon were enumerated and then a randomly selected subsample of 25 was measured to estimate the average size of individuals from that taxon in that particular stomach. Lengthweight regressions were not available for Seleno- 
teuthis scintillans $(\mathrm{n}=4)$, Diaphus dumerilii $(\mathrm{n}=1)$, or Ceratoscopelus maderensis $(\mathrm{n}=1)$ of the northwest Atlantic. The infrequent occurrence of these species suggested that they represented insignificant portions of the diet and they were, therefore, excluded from analyses using reconstructed mass (i.e. \% mass, index of relative importance, and modified mass). Unidentified species were also excluded from all methods that utilized reconstructed mass.

The index of relative importance (IRI; Pinkas et al. 1971) and modified mass (mod. mass; Gannon et al. 1997) are composites of the previous 3 methods. IRI is calculated by the following equation

$$
\mathrm{IRI}=\mathrm{FO} \times(\% \text { num }+\% \text { mass })
$$

Modified mass was adapted from the 'modified volume' method of Bigg \& Perez (1985). The steps involved in calculating modified mass are:

(1) Determine the proportion of all fishes to all squids by non-trace FO

(2) Determine the proportions of each species within these categories by total \%mass (trace and nontrace \%mass combined).

(3) Adjust the mass ratios for each species to sum to the total proportions of squids and fishes present in the diet.

(4) Readjust all values to sum to $100 \%$

We generated length-frequency distributions for pilot whale prey to determine the size classes of food consumed. Lengths given for teleosts are fork lengths and those for cephalopods are mantle lengths. The length-frequencies include length estimates of trace specimens and measurements of non-trace specimens.

Relative prey importance was calculated for all 30 whales as a group. The sample size precluded any investigation of dietary differences among age or reproductive classes.

Foraging behavior. We used metric multidimensional scaling (MDS) to investigate the possibility that whales were feeding in the vicinity of fishing vessels, to compare diets within and between sexes, to compare diets within and between the years of capture, and to compare diets within and between pods. Metric MDS was chosen over principal components analysis because it was more important to represent intersample similarity than total variation in the data. We used proportions of numerical prey abundance from each stomach in the MDS analysis. Numerical abundance was chosen because it provided the most information with the smallest error. Before performing the analysis, we applied a modified arcsine square root transformation to the proportional data to equalize variance (Rao 1973, p. 428). The metric MDS procedure was performed by the multivariate statistical program S-Plus, version 3.2 (Mathsoft, Inc., Seattle, WA, USA). The
Table 1 Globicephala melas. Long-finned pilot whale groups captured by the Distant Water Fleet (DWF) mackerel fishery and included in diet analyses. All other whales studied were captured alone $(\mathrm{n}=$ number of whales, $\mathrm{YR}=$ year, $\mathrm{MO}=$ month, $\mathrm{DD}=$ day

\begin{tabular}{|ccccc|}
\hline Group & $\mathrm{n}$ & Latitude N & Longitude W & YR MO DD \\
\hline A & 2 & $39^{\circ} 40^{\prime}$ & $72^{\circ} 26^{\prime}$ & 89325 \\
B & 7 & $39^{\circ} 31^{\prime}$ & $72^{\circ} 13^{\prime}$ & 89327 \\
C & 2 & $40^{\circ} 14^{\prime}$ & $70^{\circ} 55^{\prime}$ & 90416 \\
D & 2 & $40^{\circ} 15^{\prime}$ & $70^{\circ} 29^{\prime}$ & 91412 \\
E & 2 & $40^{\circ} 12^{\prime}$ & $70^{\circ} 28^{\prime}$ & 91416 \\
F & 4 & $40^{\circ} 15^{\prime}$ & $70^{\circ} 29^{\prime}$ & 91418 \\
\hline
\end{tabular}

greater the similarity in contents of 2 stomachs, the closer together they were placed on the MDS scatter plot (Sprules 1980). No axis labels are shown because the axes in MDS plots are arbitrary (Shepard 1974, Sprules 1980). Separate MDS analyses were performed for trace and non-trace food materials.

On 6 occasions, 2 or more pilot whales were captured together (range $=2$ to 7 individuals). Pilot whales caught at the same time and location were assumed to be from the same pod. Whales captured together were called a 'group'. The term 'group' is used in this context rather than 'pod' because it is unlikely that entire pods were captured and it is possible that 2 or more groups originated from the same pod. Capture data for all 6 groups, designated as $A$ through $F$, are shown in Table 1 The total number of whales for all 6 groups was 19 . The remaining 11 whales not shown in Table 1 were captured alone. MDS scatter plots were visually inspected for dietary trends associated with sex, group, and year of capture that might reflect foraging behavior or sampling biases.

\section{RESULTS}

\section{Relative prey importance}

Table 2 lists the scientific and common names of the 11 prey taxa identified in the pilot whale stomachs. All 30 stomachs contained trace food material, while only $22(73 \%)$ contained non-trace material. Atlantic mackerel, long-finned squid, Atlantic herring, silver hake and short-finned squid were the only prey represented by non-trace specimens. Rankings of dietary importance by non-trace methods were generally in agreement: mackerel, followed by long-finned squid, Atlantic herring, silver hake, and ommastrephid squid (Tables 3 \& 4; Figs. 2b \& 3b).

Rankings of dietary importance by the assorted trace measures varied for many species. However, the longfinned squid ranked as the most important prey spe- 
Table 2. List of prey items present in the stomachs of longfinned pilot whates incidentally captured by the DWF mackerel fishery ( $n=$ total number of individuals recovered from each species\}

\begin{tabular}{|llr}
\hline Species name & Common name & $\mathrm{n}$ \\
\hline Fishes & & \\
Ceratoscopelus maderensis & Lantern fish & 1 \\
Clupea harengus & Atlantir herring & 48 \\
Diaphus dumerili & Lantern fish & 1 \\
Merluccius bilinearls & Silver hake & 19 \\
Scomber scombrus & Atlantic mackerel & 199 \\
Squalus acanthias & Spiny dogfish & 2 \\
Unknown fish & & 3 \\
Squids & & \\
Chiroteuthis veranyl & & 83 \\
Histioteuthis reversa & & 343 \\
Loligo pealei & Long-finned squid & 3340 \\
Ommastrephidae & Short-finned squid & 820 \\
Selenoteuthis scintillans & & 4 \\
Unknown squid & & 37 \\
\hline
\end{tabular}

(a) Trace Proportion of Numerical Abundance

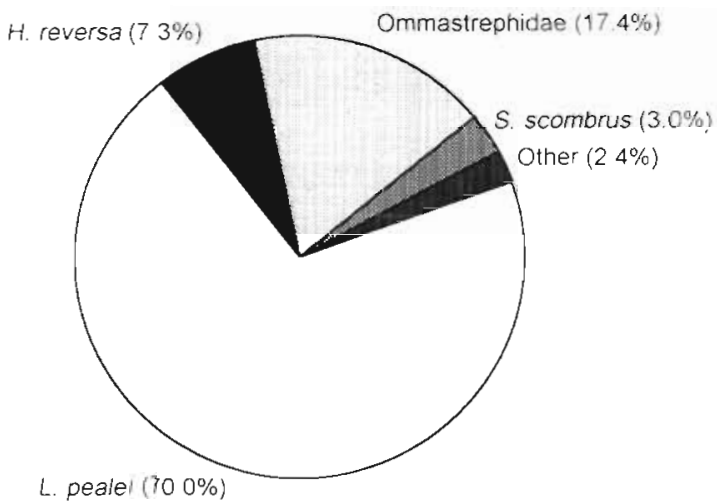

(b) Non-Trace Proportion of Numerical Abundance

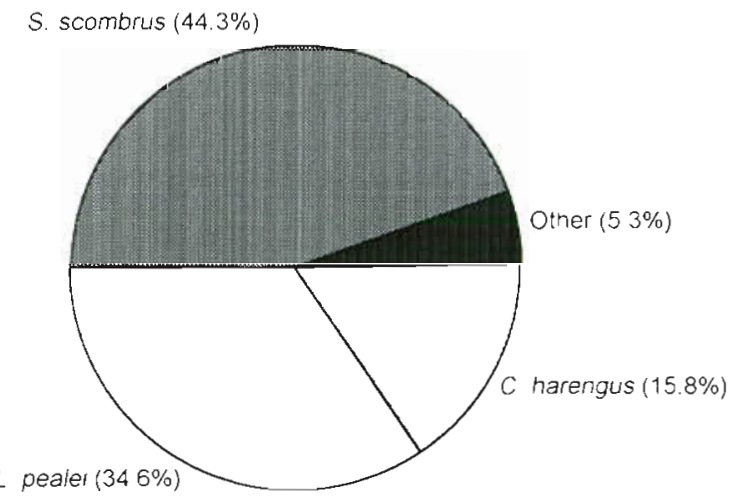

Fig. 2. Globicephala melas Composition of the plot whale diet determined by (a) trace and (b) non-trace proportion of numerical abundance
Table 3. Trace and non-trace frecpuencies of occurrence (FO), with associated ranks (\#), for the food materials of long-finned pilot whales incidentally captured in the UWF mackerel fishery

\begin{tabular}{|lrrcc|}
\hline Species & $\begin{array}{c}\text { Trace FO } \\
(\%)\end{array}$ & $\#$ & $\begin{array}{c}\text { Non-trace FO } \\
(\%)\end{array}$ & \\
\hline L. pealel & 100.0 & 1 & 54.5 & 2 \\
Ommastrephidae & 80.0 & 2 & 4.5 & 4 \\
H. reversa & 53.3 & 3 & - & - \\
C veranyi & 43.3 & 4 & - & - \\
Unknown squid & 40.0 & 5 & - & - \\
S. scombrus & 26.7 & 6 & 77.3 & 1 \\
C. harengus & 23.3 & 7 & 18.2 & 3 \\
M. bilinearis & 13.3 & 8 & 4.5 & 4 \\
S. scintillans & 6.7 & 9 & - & - \\
S. acanthias & 6.7 & 9 & - & - \\
D. dumerilii & 3.3 & 11 & - & - \\
C. maderensis & 3.3 & 11 & - & - \\
Unknown fish & 3.3 & 11 & - & - \\
& & & & \\
\hline
\end{tabular}

Table 4. Trace and non-trace indices of relative prey importance (IRI), with associated ranks (\#), for the food materials of long-finned pilot whales incidentally captured in the DWF mackerel fishery

\begin{tabular}{|c|c|c|c|c|}
\hline Species & Trace IRl & $\#$ & Non-trace IRI & \# \\
\hline L. pealel & 1.54 & 1. & 0.30 & 2 \\
\hline Ommastrephidae & 0.18 & 2 & $<0.01$ & 4 \\
\hline H. reversa & 0.04 & 3 & - & - \\
\hline S. scombrus & 0.03 & 4 & 0.88 & 1 \\
\hline C. veranyi & 0.01 & 5 & - & - \\
\hline C. harengus & $<0.01$ & 6 & 0.04 & 3 \\
\hline M. bilnearis & $<0.01$ & 6 & $<0.01$ & 4 \\
\hline S. scintillans & $<0.01$ & 6 & - & - \\
\hline S. acanthias & $<0.01$ & 6 & - & - \\
\hline
\end{tabular}

cies by every trace method and by modified mass (Tables 3 \& 4 ; Figs. 2a, 3a, \& 4). Long-finned squid remains were present in every stomach (trace $\mathrm{FO}=$ $100 \%$, non-trace $\mathrm{FO}=54.5 \%$; Table 3 ). Long-finned squid represented a minimum of $20.1 \%$ (non-trace proportion of mass; Fig $3 \mathrm{~b}$ ) and a maximum of $83.9 \%$ (trace proportion of mass; Fig. 3a) of the diet, with a modified mass of $77.1 \%$ (Fig. 4)

Atlantic mackerel were present in 24 stomachs and dominated the number of fish prey items. Mackerel had a trace FO of $26.7 \%$ but a non-trace FO of $77.3 \%$ (Table 3), indicating that well over half of the whales in the total sample $(57 \%)$ fed on mackerel just prior to death. Most trace mackerel remains ( $n=112$ ) were recovered from 1 stomach. Mackere] comprised a minimum of $3 \%$ (trace numerical abundance; Fig. 2a) and a maximum of $68.8 \%$ (non-trace proportion of mass; Fig, $3 b$ ) of the diet, with a modified mass of $17.2 \%$ (Fig. 4). 
Short-finned squid (family Ommastrephidae), although not abundant in the nontrace category, had a trace FO of $80 \%(4.5 \%$ non-trace $\mathrm{FO}$; Table 3). Short-finned squid were ranked among the top 3 most important prey items by all trace measures and by modified mass (Tables $3 \& 4$; Figs. 2a, 3a \& 4). Short-finned squid comprised at least $0.2 \%$ (by non-trace proportion of mass) and at most $17.4 \%$ (by trace numerical abundance) of the diet. The modified mass value for short-finned squid was $4.8 \%$

No other prey taxon was given consistently high importance rankings. Atlantic herring occurred in almost a third of the stomachs (trace $\mathrm{FO}=23.3 \%$, non-trace $\mathrm{FO}=$ $18.2 \%)$, but had a trace numerical abundance and trace proportion of mass of less than $1 \%$ The squids Histiotuethis reversa and Chiroteuthis veranyi were represented by trace specimens in $53 \%$ and $43 \%$ of the stomachs, respectively. However, neither $H$. reversa nor $C$. veranyi were represented by non-trace specimens. Spiny dogfish was only found in 2 stomachs, representing less than $1 \%$ of the diet by both trace numerical abundance and trace proportion of mass. No intact dogfish specimens were recovered. Silver hake represented a maximum of $5.4 \%$ of the diet by non-trace proportion of mass.

Length-frequency distributions for Atlantic mackerel and long-finned squid are given in Figs. 5 \& 6. All intact (non-trace) mackerel had fork lengths between 265 and $375 \mathrm{~mm}$ (mean $=349.2, \mathrm{SE}=30.0$; Fig. 5). Estimates of mackerel lengths from trace material averaged $381.6 \mathrm{~mm}$, with a range from 311 to $421 \mathrm{~mm}$ and standard error of $27.2 \mathrm{~mm}$. Long-finned squid mantle lengths, estimated trom trace remains, averaged $208.2 \mathrm{~mm}$ (range 37 to $436 \mathrm{~mm}, \mathrm{SE}=81.3$; Fig 6). Intact long-finned squid had a mean mantle length of $245.4 \mathrm{~mm}$ (SE $=56.8$ ).

\section{Foraging behavior}

Fig. 7 shows the MDS scatter plots of the non-trace food remains from each whale. In Fig. $7 \mathrm{a}$, individual whales are identified by either their group designation (A. to $F$ ) or a 'Z' for whales that were captured solitanly. Individuals are identified by their year of capture in Fig. 7b. There were 3 categories of non-trace stomach remains: stomachs totally lacking non-trace material (lower right cor- (a) Trace Proportion of Mass

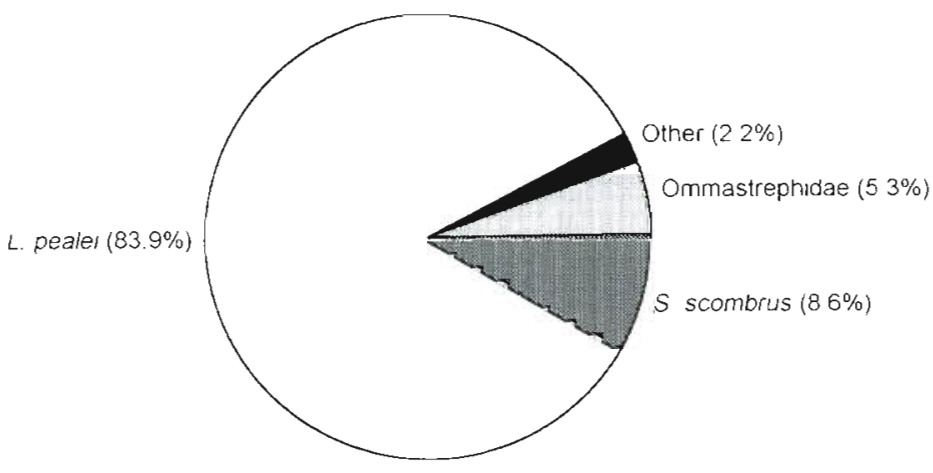

(b) Non-Trace Proportion of Mass

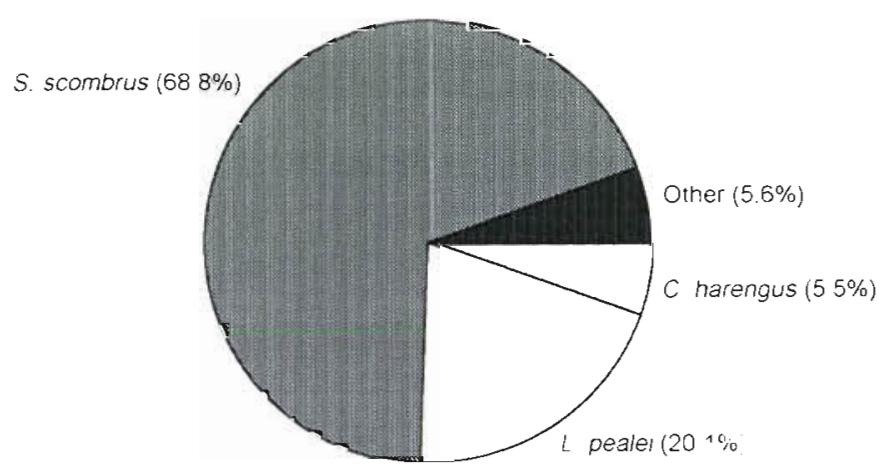

Fig. 3. Globicephala melas. Composition of the pilot whale diet determined by (a) trace and (b) non-trace proportion of reconstructed mass

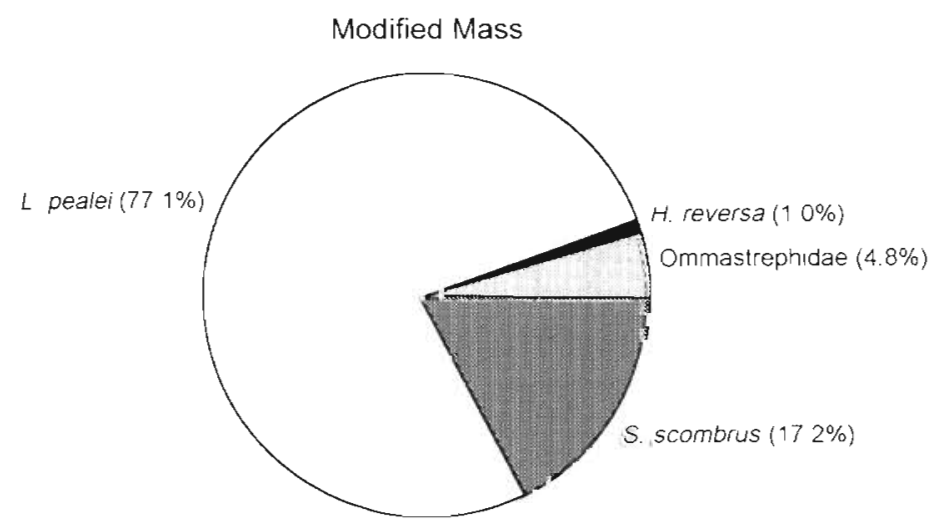

Fig. 4. Globicephala melas. Composition of the plot whale diet determined by modified mass

ner of scatter plots); stomachs having non-trace material, but few or no mackerel (middle right); and those having many non-trace mackerel (left). No patterns were associated with either group or year of capture in 


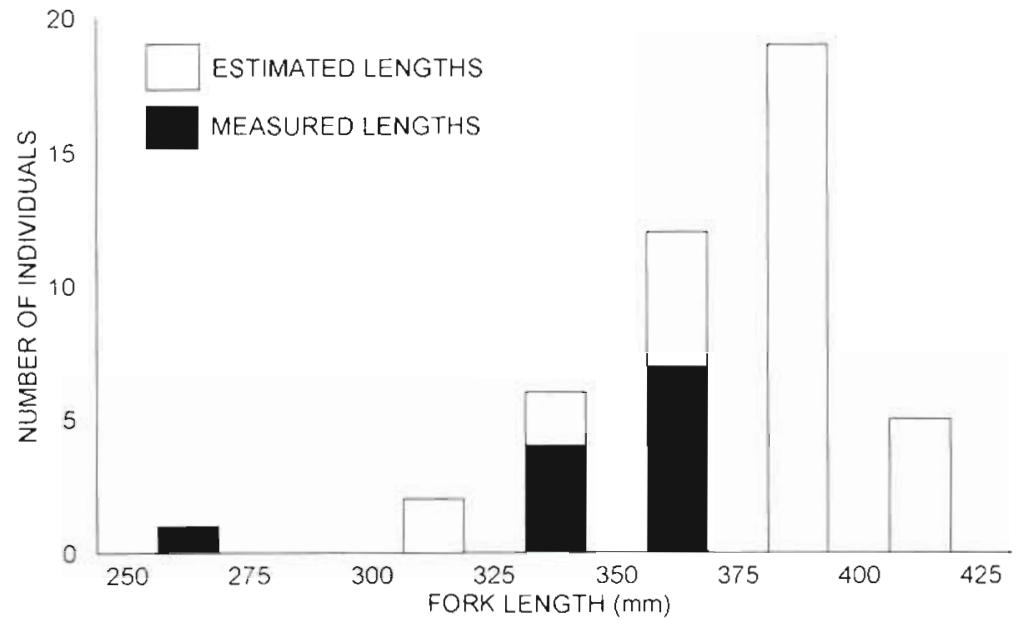

Fig. 5. Scomber scrombrus. Length-frequency distribution of trace lopen bars) and non-trace (solid bars) Atlantic mackerel recovered from pilot whale stomachs

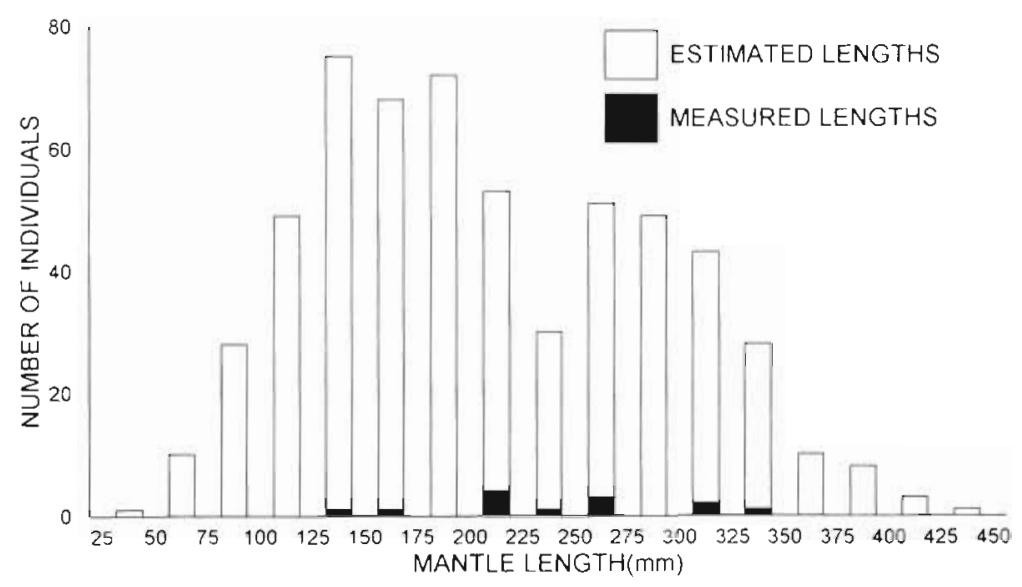

Fig. 6. Loligo pealer. Length-frequency distrubution of trace (open bars) and non-trace (solid bars) long-finned squid recovered from pilot whale stomachs

the non-trace MDS analysis. There were large differences in intact food remains between individuals of the same group (and the same year). For example, note the dispersion among members of groups B and $\mathrm{F}$ (Fig. 7 a). At the same time, however, some whales from different groups (and different years) had non-trace stomach contents that were virtually identical, signified by overlapping coordinates. There are 5 points on Fig. $7 \mathrm{a}$ and $7 \mathrm{~b}$ where individuals overlap. These graphs were slightly modified to clearly show the overlapping individuals. Asterisks (*) indicate the correct positions of overlap. The identities of concordant individuals are listed directly beneath the asterisks. Each set of overlapping coordinates on the non-trace MDS plot is a composite of members from different groups. For example, a $Z$ and a D, caught in 1990 and 1991 respec- tively, overlap at the approximate coordinates $[-0.63,-0.04]$; 1 member from group B and 2 from group $C$, which were caught in different years, overlap at $[-0.47,-0.13]$; a member of group $A$ and 2 members of group $B$ are located at $[-0.25$, $-0.18]_{;}$and an $E$ and $a \mathrm{~B}$, also caught in different years, were plotted at $[0.47$, $0.25]$. The 8 overlapping individuals at $[0.4,-0.4]$ had no non-trace stomach contents.

The results of the trace MDS analysis are given in Fig. 8. Similar to the nontrace MDS plots, Fig 8a shows the group designation and Fig. 8b shows the year of capture for each whale. All members of groups $A, B, D, E$, and $F$ are generally located in the upper right quadrant of Fig. 8a, indicating inter- and intragroup dietary similarity. Group $C$, the only group taken in 1990, is located on the left side of the graph, indicating large differences from the other 5 groups. The whales caught in 1990 are widely dispersed throughout the leftmost two-thirds of the graph, indicating high dietary diversity. The whales caught in 1991 are primarily confined to the upper right corner Trace diets of whales caught in 1989 lie between those from 1990 and 1991. Fig. 8 b implies that the diets of the whales caught in 1989 and 1991 were similar to each other but different from those caught in 1990.

MDS plots revealed no obvious dietary differences between males and females. However, since the sample is dominated by females, and no mature males are represented, it would be premature to make any definitive statement on the dietary similarities or differences between the sexes

\section{DISCUSSION}

The winter/spring diet of long-finned pilot whales off the northeastern. United States is catholic and dominated by squids. Long-finned Logio pealei squid had the highest importance of all prey by every trace measure and by modified mass. Short-finned squid Ommastrephidae, Histioteuthis reversa, and Chiroteuthis veranyi were also prominent in the trace measures.

The most striking features of the non-trace MDS data were the similarities among diets of individuals from different groups and different years (Fig. $7 a, b$ ). These re- 
(a) MDS of Non-trace Stomach Contents by Group

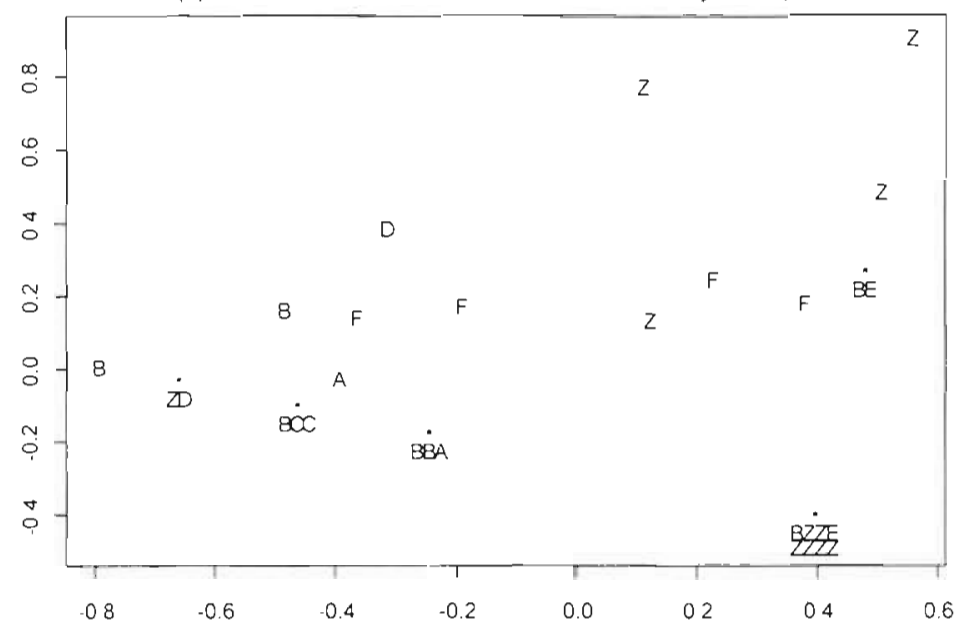

(b) MDS of Non-trace Stomach Contents by Year

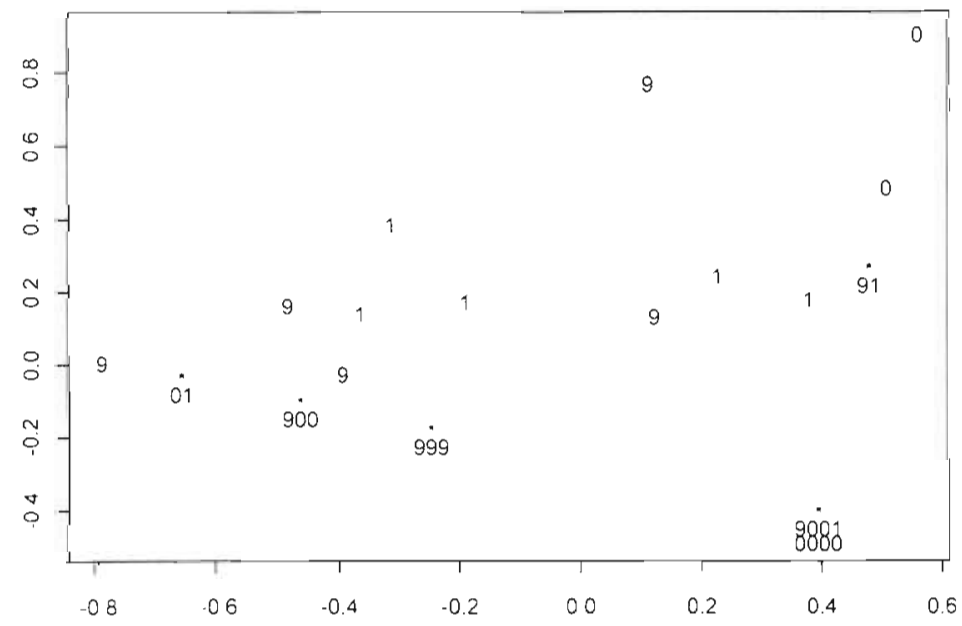

Fig. 7 Globicephala melas. Multidimensional scaling of the non-trace stomach contents from 30 pilot whales taken incidentally by the DWF mackerel fishery. Individual whales are designated by (a) their group affiliations (A to $F_{\text {; }}$ whales captured alone are designated by $Z$ ); (b) their year of capture. $\left({ }^{*}\right)$ Positions where 2 or more individuals overlap; identuties of the concordant individuals are listed directly beneath the ' $*$ '. $9=$ 1989, $0=1990,1=1991$

sults indicated a large proportion of whales had recently eaten mackerel. Over three-quarters (77.3\%) of the whales with intact prey in their stomachs had been feeding on mackerel. The similarities in intact food remains among whales from different years and different groups is in juxtaposition to the differences in trace food remains among the 3 years. The trace and non-trace MDS analyses of group and year of capture strongly support the hypothesis that many whales caught in the mackerel fishery had been opportunistically feeding on mackerel around the fishing nets at the time of death.

Intrapod dietary similarity, shown by close proximities of the members of each group in the MDS plots based on trace, or well-digested, food, suggests that pod members forage together and that pods are stable over periods of at least a few days, in agreement with the conclusions of Amos et al. (1993). Variation among groups suggests that there may be dietary differences among pods, although this may have been an artifact of yearly changes in the diet. The between-year differences in trace food remains shown by the MDS analysis (Fig 8b) appear to be the result of changes in consumption of long-finned and short-finned squids. Long-finned squid strongly dominated the trace diets in 1989 and 1991 (72.3\% and $90.5 \%$ numerical proportion, respectively), while short-finned squid were unimportant in both years $(3.7 \%$ and $1.2 \%$, respectively). However, in 1990, short-finned squid $(51.1 \%)$ became more abundant than long-finned squid (33.8\%) in pilot whale stomachs. Standardized fisheries resource bottom trawl surveys conducted each spring over the same 3 yr period did not register any changes in long-finned squid abundance that corresponded to the observed dietary changes (Northeast Fisheries Science Center, NOAA/ National Marine Fisheries Service, Woods Hole, MA, USA, unpubl. data). But commercial long-finned squid landings (not adjusted for fishing effort) did reflect the trend found in the pilot whale stomach contents (CUD 1995). Squid fishing vessels and pilot whales presumably concentrate their efforts in areas of local abundance for long-finned squid, so concordance is expected. Multispecies fisheries resource surveys have broader goals and may miss or undersample areas with high longfinned squid densities, making it difficult to detect population trends. Significant temporal and spatial variability in densities is suggested by this species' annual, semelparous life history (Brodziak \& Macy 1996)

The sizes of long-finned squid and Atlantic mackerel recovered from pilot whale stomachs are similar to the size classes targeted by the former DWF mackerel fishery (Overholtz \& Waring 1991) and the present domestic long-finned squid fishery (CUD 1995 , p. 112). The length-frequency distribution of longfinned squid suggests that the whales consumed members of at least 2 cohorts. Mackerel and long-finned squid were the only species for which meaningful length-frequency distributions could be generated.

One of the most vexing biases in stomach contents analyses is caused by differential. digestibility of prey. In the stomachs of marine mammals, squid flesh digests faster than that of fishes (Bigg \& Fawcett 1985). 
(a) MDS of Trace Stomach Contents by Group

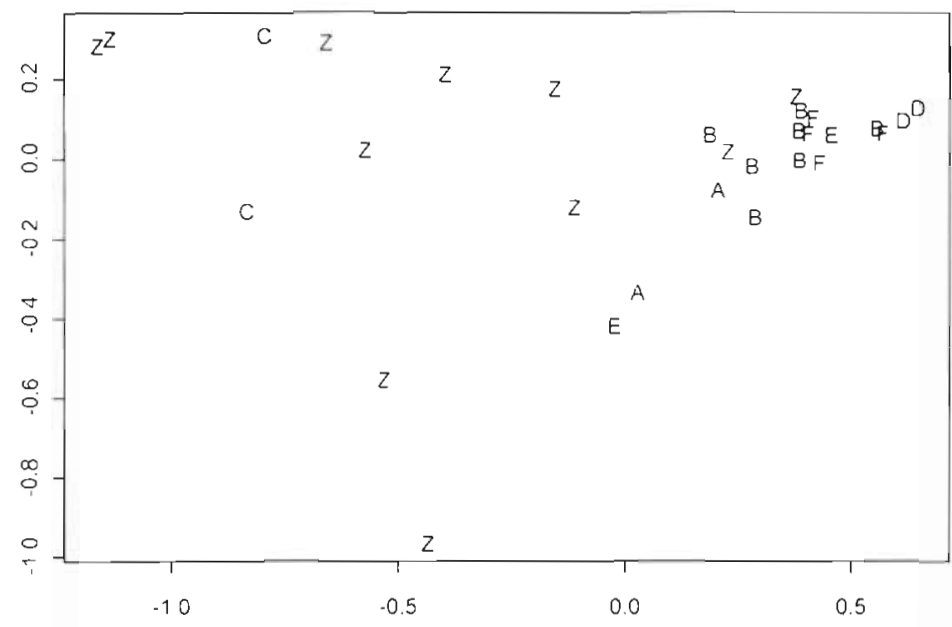

(b) MDS of Trace Stomach Contents by Year

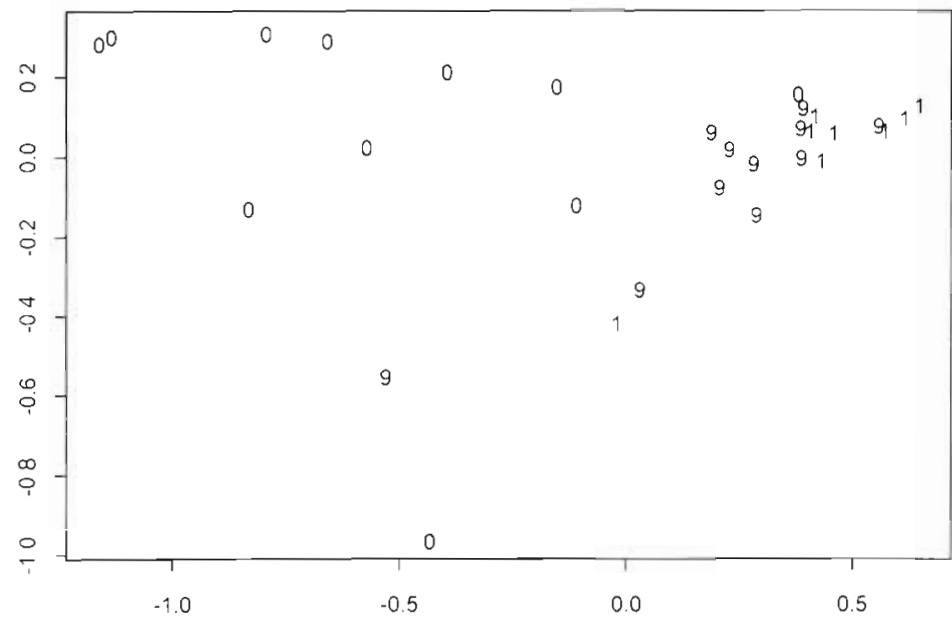

Fig. 8. Globicephala melas. Multidimensional scaling of the trace stomach contents from 30 pilot whales taken incidentally by the DWF mackerel fishery. Individual whales are designated by (a) their group affiliations (A to $\mathrm{F}$; whales captured alone are designated by $Z$ ); (b) their year of capture $9=1989,0=1990,1=1991$

However, fish are completely digestible while squid beaks are known to persist in the stomachs of predators (Bigg \& Fawcett 1985). Therefore, analyses considering only intact prey will underestimate the importance of squids in the diet, whereas those that rely solely on hard parts will likely overestimate the importance of squid. Because the relative magnitudes of these biases are unknown, it is prudent to perform separate analyses on both trace and non-trace material, thereby obtaining ranges of estimated prey importance values that are likely to encompass the actual values.

Modified mass was an attempt at simultaneously reducing the biases caused by differences between fishes and squids regarding digestion rates of soft tis- sues and durability of hard parts. Based on these differences, it is reasonable to believe that for a predator that eats both fish and squid, the actual proportion of a fish species in the diet should be greater than its values for trace \%num and trace \%mass but less than its values for non-trace \%num and $\%$ mass. Likewise, the actual proportion of the diet represented by a squid species should be greater than its values for non-trace \%num and non-trace \% mass but less than its values for trace \%num and trace \% mass. Using this as a benchmark, modified mass appears to have performed well. The only species that fell outside of its expected range in modified mass was long-finned squid. The modified mass value for long-finned squid was expected to be between $34.6 \%$ (non-trace $\%$ num; non-trace $\%$ mass $=20.1 \%$ ) and $70.0 \%$ (trace \%num; trace \%mass $=83.9 \%)$. The actual modified mass value was $77.1 \%$. Because modified mass performed well according to our criteria, we relied heavily on it while drawing our conclusions.

The prey assemblage reported here is similar to that found by Gannon et al. (1997), who used identical methods to study the diet of Globicephala melas stranded along the northeastern United States. Only 2 species (Diaphus dumerilii and Ceratoscopelus maderensis), each represented by 1 individual and both recovered from the same stomach, were present in the fishery bycatch sample but not in the sample of stranded animals. Similarly, only 1 taxon, hake Urophycis spp., was present in the stomachs of the stranded whales but absent from the current sample. Four species (Chiroteuthis veranyi, Selenoteuthis scintillans, Atlantic herring, and spiny dogfish) discovered in the stranded whales, which were previously unknown in the $G$. melas diet, were also found here This suggests that these species are regular components of the diet and not just artifacts of unusual circumstances preceding either stranding or incidental capture. Histioteuthis reversa, which was also found in both samples, had previously only been reported in the diet of eastern North Atlantic long-finned pilot whales (Desportes \& Mouritsen 1993).

Our analyses of intact prey remains yielded 5 species while the analyses that included trace remains produced 11 species. Early studies in the western North Atlantic relied primarily on intact food and recorded far fewer prey species in the stomachs of long-finned pilot whales (i.e. Sergeant 1962, Mercer 1967, Waring et al. 1990, Overholtz \& Waring 1991). Gannon et al. 
(1997) and this study added 8 new species to the list of Globicephala melas prey items recorded in the northwest Atlantic, indicating the value of trace food materials in assessing the range of dietary items.

The results of the present study were similar to those of Gannon et al. (1997) with respect to the relative prey importance values obtained from all trace and modified mass measures. Long-finned squid dominated all trace measures and modified mass in both samples, as well as the non-trace sample from the stranded whales. However, non-trace analyses of whales caught by the mackerel fishery, both here and in Overholtz \& Waring (1991), found mackerel were dominant. This reinforces the conclusion that non-trace analyses are especially susceptible to biased sampling, in this case taking whales in a mackerel fishery.

Pilot whales primarily eat long-finned squid, but we speculate that they switch to other schooling species of similar size when the costs of capturing long-finned squid become high, such as during daylight. Adult long-finned squid are vertical migrators, being demersal by day and ascending into the water column at night (Roper \& Young 1975, Roper et al. 1984). However, net retrieval during trawling operations probably herds schools of the target species toward the surface. The resulting high prey densities near the surface provide easy feeding opportunities for the whales throughout the day and night. When pilot whales encounter squid fishing vessels, they are able to feed effectively on their primary prey at any time. When long-finned squid are less available, the whales may take advantage of other species that become concentrated by human fishing activities. These conclusions are consistent with the findings of Waring et al. (1990) who discovered that the pilot whale bycatch rate in the DWF mackerel fishery was significantly higher during the day than the night but that there was no significant difference between day and night bycatch rates in the DWF long-finned squid fishery.

Different methods of assessing dietary importance yielded a wide range of results, so considerable effort must be taken to ensure that the results of food habits studies portray the actual diet or are consistent and comparable. We concur with Hyslop's (1980) advice that food habits investigators employ at least 1 method measuring the amount (frequency of occurrence or numerical abundance) and 1 measuring the bulk (mass or volume) of food material. We further suggest that each of these methods be applied separately to both trace and non-trace materials to reveal potential biases, such as those caused by differential digestion, differential passage, and opportunistic feeding on prey items made more accessible by human activities. Analyses that include trace data (a record of the diet over a period of days) are more likely to yield a repre- sentative picture of the overall diet than analyses based only on non-trace data (a record of the diet over a period of hours) The abundance of some species in the trace material that were absent or uncommon in the non-trace material (for example, short-finned squid Ommastrephidae Histioteuthis reversa, and Chiroteuthis veranyi) indicates that analyses of intact food items alone are inadequate to accurately describe the diet. Analytical technique and sample source clearly must be controlled for when comparing the results of different food habits studies.

There are still large gaps in our knowledge of the food habits of Globicephala melas off the northeastern U.S. Of the 45 whales included in the combined food habits studies in this region, none were adult males and only one, a calf, came from outside the February to May period. Seasonal, sexual, and pod-specific variability in diet is dramatically undersampled at present.

Acknowledgements. We thank the fisheries observers of the Manomet Observatory and the National Marine Fisheries Service for their dedication in collecting quality tıssue samples and associated data under difficult field conditions. Trevor Spradlin and Krystal Tolley were invaluable durng the pungent stomach dissections Chuck Lea, Mike Vecchıone, and Mike Sweeney assısted in cephalopod ıdentification. Brian O'Gorman of the National Marine Fisheries Service's Northeast Fisheries Science Center provided fisheries resource survey data. Constructive criticism from Kevin Curry, Janet Gray, John Jahoda, Walter Morin, and 3 anonymous reviewers substantially improved the manuscript. Nancy DiMarzio helped with some of the figures. Conversatıons with William Watkins on cetacean feeding strategies were enlightening and his encouragement has been greatly appreciated. This research was funded by the National Marine Fisheries Service under Co-operative Agreement no. NA47FL0314. This is contribution no. 9419 from the Woods Hole Oceanographic Institution.

\section{LITERATURE CITED}

Amos B, Bloch D, Desportes G, Majerus TMO, Bancroft DR, Barrett JA, Dover GA (1993) A review of molecular evidence relating to social organisation and breeding system in the long-finned pilot whale. In: Donovan GP, Lockyer $\mathrm{CH}$, Martin AR (eds) IWC Special Issue 14: Biology of Northern Hemisphere pilot whales. International Whaling Commission, Cambrudge, UK, p 209-218

Bigg MA, Fawcett 1 (1985) Two biases in diet determination of northern fur seals (Callorhmus ursinus). In: Beddington JR, Beverton RJH, Lavigne DM (eds) Marine mammals and fısheries. George Allen \& Unwin Ltd, London, p $284-291$

Bigg MA, Perez MA. (1985) Modified volume: a frequencyvolume method to assess marine mammal food habits. In: Beddington JR, Beverton RJH, Lavigne DM (eds) Marine mammals and fisheries. George Allen \& Unwin Ltd, London, p 277-283

Bloch D, Lockyer C, Zachariassen M (1993) Age and growth parameters of the long-finned pilot whale off the Faroe Islands. In: Donovan GP, Lockyer CH, Martin AR (eds) IWC Special Issue 14: Biology of Northern Hemisphere 
pilot whales. International Whaling Commission, Cambridge, UK, p 163-208

Brodziak JKT, Macy WK (1996) Growth of long-finned squid Loligo pealei, in the northwest Atlantic. Fish Bull 94 $212-236$

CUD (Conservation and Utılization Division. Northeast Fisheries Science Center) (1995) Status of the fishery resources off the northeastern United States for 1994. NOAA Tech Memo NMFS-NE-108, Research Communications Unit, Northeast Fisheries Science Center, Woods Hole, MA

Desportes G, Mouritsen R (1993) Preliminary results on the diet of long-finned pllot whales off the Faroe Islands. In: Donovan GP, Lockyer CH, Martin AR (eds) IWC Special Issue 14 Biology of Northern Hemisphere pilot whales. International Whaling Commission, Cambridge, UK, p 305-324

Desportes G, Saboureau M, Lacroix A (1993) Reproductive maturity and seasonality of male long-finned pilot whales off the Faroe Islands. In: Donovan GP, Lockyer CH, Martin AR (eds) IWC Special Issue 14: Biology of Northern Hemisphere pilot whales. International Whaling Commission, Cambridge, UK, p 233-262

Gales R, Pemberton D (1992) Stomach contents of long-finned pilot whales (Globicephala melas) and bottlenose dolphuns (Tursiops truncatus) in Tasmania. Mar Mamm Sci 8(4): $405-413$

Gannon DP, Read AJ, Craddock JE, Mead JG (1997) Stomach contents of long-finned pilot whales (Globicephala melas) stranded along the U.S. mid-Atlantic coast. Mar Mamm Sci 13(3):in press

Hyslop EJ (1980) Stomach contents analysis-a review of methods and their application. J Fish Biol 17:411-429

Kasuya T, Sergeant DE, Tanaka K (1988) Re-examination of life history parameters of long-finned pilot whales in the Newfoundland waters. Sci Rep Whales Res Inst 39: $103-119$

Kenney RD, Hyman MAM, Winn HE (1985) Calculation of standing stocks and energetic requirements of the cetaceans of the northeast United States outer continental shelf. NOAA Tech Memo NMFS-F/NEC-41

Martin AR, Reynolds P, Richardson MG (1987) Aspects of the biology of pilot whales (Globicephala melaena) in recent mass strandings on the British coast. J Zool (Lond) 211 $11-23$

This article was submitted to the editor
Martin AR, Rothery P (1993) Reproductive parameters of female long-finned pilot whales (Clobicephala melas) around the Faroe Islands. In: Donovan GP, Lockyer $\mathrm{CH}$, Martin AR (eds) IWC Special Issue 14: Biology of Northern Hemisphere pilot whales. International Whaling Commission, Cambridge, UK, p 263-304

Mercer MC (1967) Wintering of pilot whales, Globicephala melaena, in Newfoundland inshore waters. J Fish Res Bd Can 24:2481-2484

Overholtz WJ, Waring GT (1991) Diet composition of pilot whales Globicephala sp. and common dolphins Delphinus delphis in the Mid-Atlantic Bight during spring 1989. Fish Bull 89:723-728

Payne PM, Heinemann DW (1993) The distribution of pilot whales in shelf/shelf-edge and slope waters of the northeastern United States, 1978-1988. In: Donovan GP, Lockyer CH, Martin AR (eds) IWC Special Issue 14: Biology of Northern Hemisphere pilot whales. International Whaling Commission, Cambridge, UK, p 51-68

Pinkas L, Oliphant MS, Iverson ILK (1971) Food habits of albacore, bluefin tuna, and bonito in Californa waters. California Dept Fish Game Fish Bull 152:1-105

Rao CR (1973) Linear statistical inference and its applications, 2nd edn. John Wiley \& Sons, New York

Roper CFE, Sweeney MJ, Nauen CE (1984) FAO Species Catalogue. Cephalopods of the World. An annotated and illustrated catalogue of species of interest to fisheries. FAO Fish Synop, Vol 3, p $97-98$

Roper CFE, Young RE (1975) Vertical distribution of pelagic cephalopods. Smithson Cont Zool 209:1-51

Sergeant DE (1962) The biology of the pilot or pothead whale Globicephala melaena in Newfoundland waters. Bull Fish Res Bd Can 132

Shepard RN (1974) Representation of structure in similarity data: problems and prospects. Psychometrika 39: $373-421$

Sprules WG (1980) Nonmetric multidimensional scaling analysis of temporal variation in the structure of limnetic zooplankton communities. Hydrobiologia 69(1-2):139-146

Waring GT, Gerrior P, Payne PM, Parry BL, Nicolas JR (1990) Incidental take of marine mammals in foreign fishery activities off the northeast United States, 1977-1988. Fish Bull 88:347-360

Manuscript first received: September 23, 1996 Revised version accepted: January 15, 1997 